\title{
Desafios de Pessoas Idosas na utilização de Smart TVs: avaliando a comunicabilidade do NET Now
}

\author{
Carmen Scorsatto Brezolin \\ PPGCC - Escola Politécnica - PUCRS \\ Porto Alegre, RS \\ carmen.brezolin@edu.pucrs.br
}

\author{
Fernando Wolf Bona \\ PPGCC - Escola Politécnica - PUCRS \\ Porto Alegre, RS \\ fernando.wolf@edu.pucrs.br
}

\author{
Telcio Elui Cardoso \\ PPGCC - Escola Politécnica - PUCRS \\ Porto Alegre, RS \\ telcio.cardoso@edu.pucrs.br
}

\author{
Milene Silveira \\ PPGCC - Escola Politécnica - PUCRS \\ Porto Alegre, RS \\ milene.silveira@pucrs.br
}

\author{
Afonso Sales \\ PPGCC - Escola Politécnica - PUCRS \\ Porto Alegre, RS \\ afonso.sales@pucrs.br
}

\begin{abstract}
The increase in the number of users of the Smart TVs has been very fast: just between 2016 and 2017, there has been an expansion of more than 7 million users. At the same time, considering the global estimates referring to the increase of longevity, it can be predicted a gradual increment of elderly people utilizing these devices in the coming years, which highlights the importance of perfecting their quality of use. In this context, the objective of the present study is to evaluate what are the main challenges elderly people face while using Smart TVs, focusing on a specific application, known as NET Now. To conduct this study, the focus was on the quality of use of communicability, analysed through the application of two evaluation methods: the Semiotic Inspection Method, applied by one evaluator, and the Communicability Evaluation Method, applied to six participants aged between 60 and 80 years. It has been observed that both methods indicated problems related to different communicability breakdowns, emphasizing the importance of this kind of evaluation in order to improve the quality of use of interactive systems.
\end{abstract}

\section{KEYWORDS}

Smart TV, Televisores Inteligentes, Pessoas Idosas, Avaliação de Comunicabilidade, Inspeção Semiótica

\section{INTRODUÇÃO}

Em 2017, cerca de 20,6 milhões de pessoas de 10 anos ou mais acessaram a internet pelas chamadas Smart TVs (televisões), representando $16,3 \%$ da população que utilizou internet [1]. Esse tipo de acesso aumentou, de 16,1\% em 2017 para 23,3\% em 2018 e esse acelerado crescimento ocorreu em todas as regiões do país[2].

Considerando este contexto, no caso de emissoras de TV aberta e a cabo, é inevitável a migração para a internet, com a criação de serviços de streaming de vídeos que oferecem produções já exibidas nos canais tradicionais e que podem ser facilmente acessadas via qualquer dispositivo com acesso a internet[3]. Segundo Freitas e Lima[3], num futuro próximo as plataformas televisivas e os serviços de streaming tendem a se tornar cada vez mais unificados, proporcionando facilidade no acesso ao conteúdo para o espectador.

Assim como crescem os serviços de streaming de vídeo, aumenta também a longevidade da população. De acordo com a Organização Mundial de Saúde (OMS), o número de pessoas com idade superior a
60 anos chegará a 2 bilhões de pessoas até 2050, o que representará um quinto da população mundial [4]. Ao considerarem-se, então, essas estimativas globais de aumento de longevidade e, consequentemente, o crescimento da população idosa, podemos vislumbrar um aumento do número de usuários dos serviços anteriormente citados e, consequentemente, a necessidade de se aprimorar a qualidade de uso da interação com estes serviços, considerando o perfil deste público.

Em vista deste cenário, o objetivo do estudo a ser apresentado é analisar quais os principais desafios de pessoas idosas ao utilizarem Smart TVs. Para isto, foi estabelecido, como foco, o serviço do NET Now e, como critério de qualidade de uso, a comunicabilidade. Para a análise deste critério foram utilizados os dois métodos de avaliação a ele associados: o Método de Inspeção Semiótica (MIS) e o Método de Avaliação de Comunicabilidade (MAC).

Este trabalho está organizado da seguinte forma: a Seção 2 apresenta o referencial teórico relacionados a este tema; na Seção 3, o detalhamento da metodologia; na Seção 4, a aplicação do MIS; na Seção 5, a aplicação do MAC; na Seção 6, discussões a partir resultados obtidos em cada método, na Seção 7, apresenta as limitações do estudo, e, por fim, na Seção 8, considerações finais desse trabalho, seguidas pelas referências utilizadas em sua construção.

\section{REFERENCIAL TEÓRICO}

Nesta seção serão abordados os fundamentos principais utilizados como base para este trabalho: Smart TVs e comunicabilidade, neste último destacando-se os métodos de avaliação MIS e de MAC.

\section{$2.1 \quad$ Smart TVs}

Existem três termos que definem o conceito de Smart TV: convergente, interligada e inteligente. Em suma, Smart TV descreve a integração da Internet com televisões, é a fusão e convergência da tecnologia entre TVs, smartphones, tablets, computadores e outros dispositivos de comunicação. Esses dispositivos são habitualmente usados por várias pessoas, permitindo ao usuário um acesso a múltiplos canais de conteúdo [5].

Uma das vantagens das Smart TVs é que essa permite assistir diferentes conteúdos, a qualquer hora, pausando quando quiser, recursos esses que vem conquistando cada vez mais o público [6]. Esta combinação única de TV com processamento e conectividade torna a Smart TV a principal escolha para entretenimento doméstico[7]. Segundo Alam, Khusro e Naee[7], ela é mais interativa, porém, 
mantê-la como um dispositivo enxuto é uma questão que precisa de mais pesquisas no campo de Interação Humano-Computador (IHC), pois sua natureza híbrida, ao oferecer muitos conteúdos, cria problemas de sobrecarga cognitiva.

\subsection{Comunicabilidade}

A comunicabilidade é um conceito advindo da Engenharia Semiótica e trata da qualidade de comunicação entre designers e os usuários. Por esta comunicação, o designer informa ao usuário quem ele acredita que o usuário seja, o que ele pode fazer e como interagir com o sistema [8]. Ainda segundo De Souza[8], a interação humano-computador possivelmente terá mais sucesso se designers forem apresentados como os verdadeiros remetentes de um tipo de mensagem altamente peculiar: uma mensagem que envia e recebe mensagens (um artefato de metacomunicação). Para o designer, essa perspectiva deve proporcionar uma maior consciência do conteúdo da mensagem e para os usuários, essa perspectiva deve fornecer um conjunto mais rico e preciso de crenças e expectativas sobre o comportamento dos sistemas [8].

Para avaliar a comunicabilidade de um sistema computacional interativo, a Engenharia Semiótica oferece os métodos de Inspeção Semiótica e o de Avaliação de Comunicabilidade, os quais serão detalhados a seguir.

2.2.1 Método de Inspecão Semiotica (MIS). O MIS avalia a comunicabilidade através da inspeção do sistema, examina a diversidade de signos aos quais os usuários são expostos enquanto interagem com os artefatos. O conceito de signo está no cerne da inspeção semiótica[9], e são exemplos de signos frequentes nas interfaces dos sistemas de computador, citados pelas autoras, os widgets, imagens, palavras, cores, estruturas de diálogo, layouts gráficos, etc. O método possui cinco etapas: (1) inspeção dos signos metalinguísticos; (2) inspeção dos signos estáticos; (3) inspeção dos signos dinâmicos; (4) contraste e comparação entre as mensagens identificadas em cada uma das inspeções; e (5) apreciação da qualidade da metacomunicação [10].

Existem três classes distintas de signos no discurso interativo do representante do designer[11]: signos estáticos, signos dinâmicos e signos metalinguísticos. Os signos estáticos são elementos de interface cujo significado é interpretado independentemente das relações temporais e causais, ou seja, o contexto de interpretação é limitado aos elementos que estão presentes na interface em um único momento no tempo. São exemplos de signos estáticos, a estrutura do layout, as opções de menu e os botões da barra de ferramentas. Os signos dinâmicos estão ligados a aspectos temporais e causais da interface, ou seja, à própria interação. Eles surgem com a interação e devem ser interpretados com referência a ela. Por exemplo, quando um usuário seleciona uma opção do menu, a associação causal entre a seleção do menu e a caixa de diálogo que o segue é um sinal dinâmico, que só pode ser expressa ao longo do tempo, ou seja, os signos estáticos e dinâmicos estão intrinsecamente relacionados. Os signos metalinguísticos se referem a outros signos de interface, estáticos, dinâmicos ou mesmo metalinguísticos (em referência recursiva). Normalmente, eles vêm na forma de mensagens de ajuda ou de erro, avisos, diálogos de esclarecimento, dicas e assim por diante. Com signos metalingüísticos, designers explicitamente comunicam aos usuários os significados codificados no sistema e como eles podem ser usados[11].

Apesar de os métodos de avaliação por inspeção permitirem ao avaliador antever ou identificar problemas que os usuários podem vir a ter, como são baseados apenas na experiência do avaliador e com base em hipóteses sobre os usuários, eles podem ser complementados com a aplicação de métodos que envolvam a participação dos usuários, como o Método de Avaliação da Comunicabilidade.

2.2.2 Método de Avaliação da Comunicabilidade (MAC). O MAC foi proposto para analisar a metacomunicação com foco na sua recepção pelo usuário, e baseia-se na observação de como um pequeno grupo interage com um sistema específico. Mesmo dentro dos limites dessa reconstrução parcial da metacomunicação, esse método pode produzir uma riqueza de resultados pois as experiências reais dos usuários trazem surpresas aos olhos dos pesquisadores. Esses podem então explorar, analisar e interpretar aspectos de metacomunicação, surgidos da imprevisibilidade presente em ambiente comunicativo [11].

No MAC, os sistemas são vistos como uma mensagem (sobre as necessidades e expectativas previstas dos usuários) de designers para usuários. Esta mensagem pode enviar e receber outras mensagens (com as quais os usuários tentam atender às suas reais necessidades e expectativas). Nessa perspectiva, um sistema é uma espécie de "representante do discurso" para o designer[12].

Segundo de Souza e Leitão[11], os avaliadores devem procurar identificar e anotar todos os sinais de quebras comunicativas na interação do usuário e na entrevista pós-teste. O avaliador assiste à gravação de todas as sessões e realiza o trabalho de segmentálas, analisando-as para identificar todas as evidências de quebras comunicativas. Para cada quebra identificada, o avaliador associa uma das treze etiquetas de comunicabilidade propostas (Tabela 1).

Tabela 1: Etiquetas [11]

\begin{tabular}{l}
\hline \hline Avaliação Comunicabilidade - Etiquetas \\
\hline 1. Cadê? (Where is?) \\
2. E agora? (What now?) \\
3. O que é isto? (What's this?) \\
4. Epa! (Oops!) \\
5. Onde estou? (Where am I?) \\
6. Assim não dá! (I can 't do it this way.) \\
7. Por que não funciona? (Why doesn 't it?) \\
8. Ué, o que houve? (What happened?) \\
9. Para mim está bom... (Looks fine to me...) \\
10. Desisto. (I can 't do it.) \\
11. Vai de outro jeito. (I can do otherwise.) \\
12. Não, obrigado. (Thanks, but no, thanks.) \\
13. Socorro! (Help!)
\end{tabular}

\section{METODOLOGIA}

Esta seção descreve o design do estudo e o funcionamento do serviço NET Now.

\subsection{Design do Estudo}

Esse estudo utilizou conceitos e métodos da Engenharia Semiótica para avaliar a qualidade da interação de pessoas em idades entre 60 e 80 anos, com Smart TVs, com foco no critério de comunicabilidade. Para avaliar a comunicabilidade utilizamos o MIS e MAC, descritos anteriormente. 
Seguindo o proposto pelo MIS, foram, primeiro, analisados os signos metalinguisticos, estáticos e dinâmicos. Na Tabela 2, estão listadas as telas do NET Now e os signos analisados durante o nosso estudo na tela de Seleção de Filmes.

Tabela 2: Inspeção Semiótica

\begin{tabular}{ll}
\hline \hline Signo & Tipo de signo \\
\hline Menu Principal & Estático \\
Ícone Filme & Estático \\
Navegação & Estático \\
Pesquisa Filmes & Estático \\
Lista Filmes Pesquisa & Dinâmico \\
Data/Hora & Dinâmico \\
Carregamento & Dinâmico \\
Paginação & Dinâmico \\
Informações Filme & Metalinguistico \\
\hline
\end{tabular}

Para o MAC, do serviço NET Now, foi solicitado, aos participantes, a tarefa de realizar a busca do filme com o nome "La La Land". O plano de testes apresentado na Tabela 3 foi criado para orientar o estudo.

Tabela 3: Plano de Teste para MAC

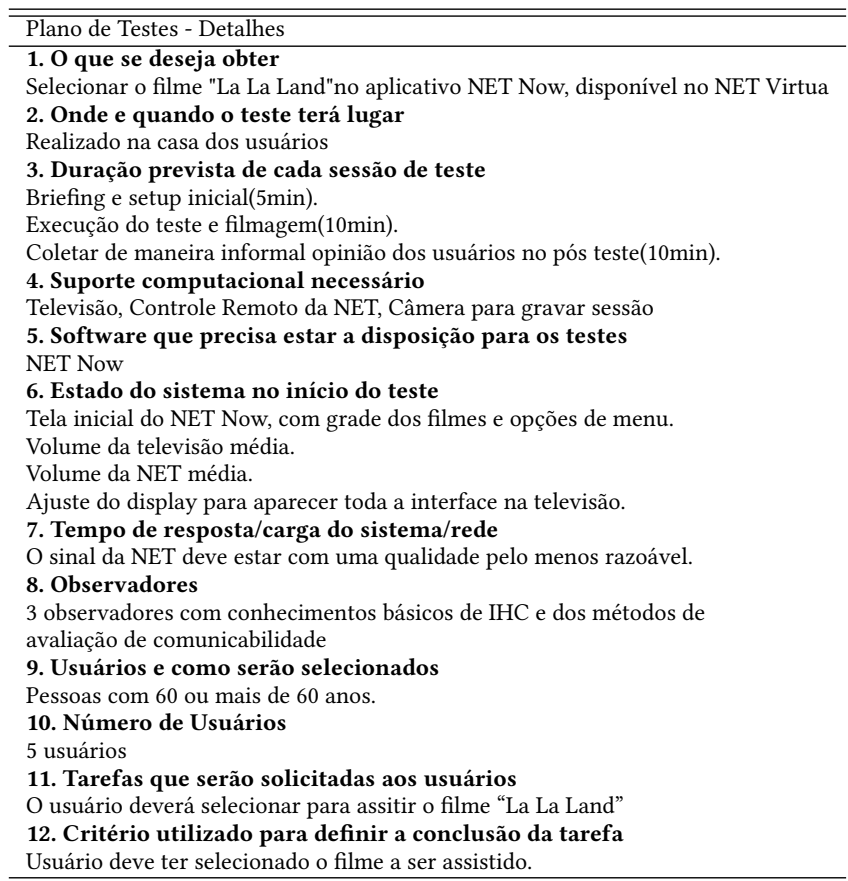

\subsection{NET Now}

O NET Now é um serviço de vídeos sob demanda, exclusivo para quem é cliente da operadora de televisão a cabo NET. Além do aparelho para recepção do sinal de TV, a empresa também disponibiliza um controle remoto personalizado para os clientes. Esse controle possui uma série de atalhos que facilitam a navegação na plataforma conforme a figura 1. Utilizando o controle remoto, para acessar diretamente a NET Now, pode-se clicar no botão de número $23(\mathrm{NOW})$ e abrirá diretamente a tela inicial ilustrado na figura 2. Outro caminho para acessar a tela inicial da NET Now é selecionando no controle remoto o botão de número 22 (MENU) e abre então as opções do menu da Net, conforme figura 3, que possibilita navegar até a opção Now, localizada na segunda linha desse menu. A descrição do controle e todas suas funcionalidades podem ser encontrados no site da operadora ${ }^{1}$. Por fim, no NET Now, os usuários conseguem ter acesso a conteúdos como filmes, musicas e séries [13].

O NET Now foi escolhido como objeto de estudo por ser o serviço que os participantes em potencial assinavam em suas casas.

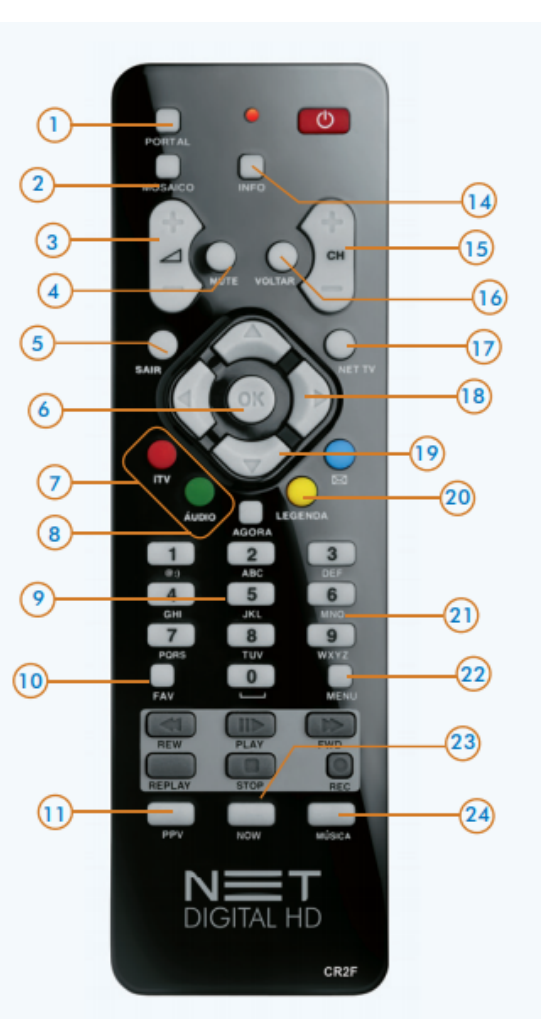

Figura 1: Controle da NET [14]

\section{INSPEÇÃO SEMIÓTICA}

A fim de se delimitar o escopo da inspeção, o cenário utilizado foi a tela inicial do NET Now, conforme a figura 2, em que o menu principal se apresenta de modo vertical, com opções disponíveis no lado esquerdo da tela, agrupando os conteúdos em diversas categorias (Recomenda - Cinema - Programas de TV - Kids - Séries - Musicas - Destaques - Adultos - Busca - Meus Videos - Sair).

Seguindo as etapas propostas pelo MIS, primeiro foram analisados os signos metalinguísticos, estáticos e dinâmicos já destacados na Tabela 2.

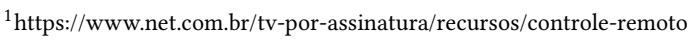




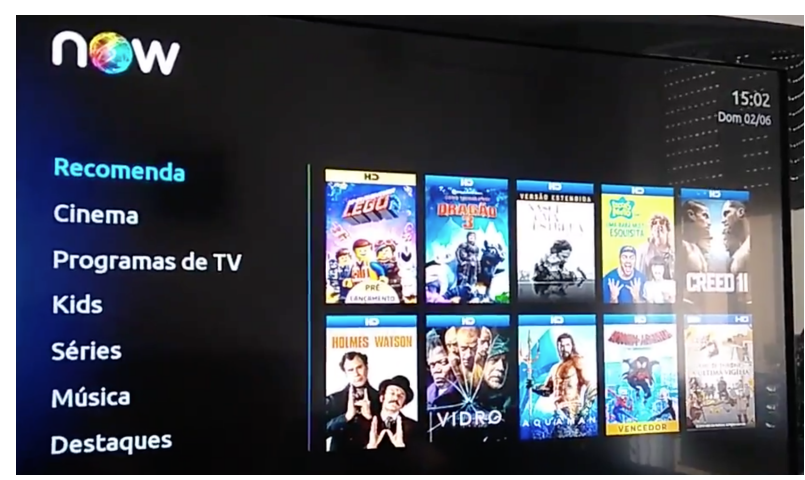

Figura 2: Tela Inicial NET Now

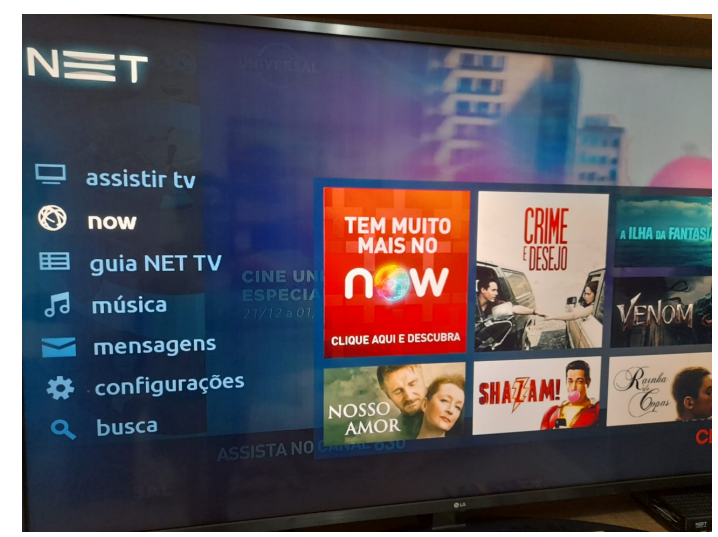

Figura 3: Menu da NET

\subsection{Etapa 1 - Inspeção dos signos metalingüísticos}

Nesta etapa foi realizada uma inspeção na documentação disponível sobre a ferramenta em análise, buscando a metamensagem do designer para o usuário. Ao acessar a tela inicial do NET Now (figura 2), não foi encontrado documentação e ajuda que fornecessem dicas referentes aos usuários esperados pela plataforma. Pelo site da NET $\mathrm{Now}^{2}$, as informações encontradas estavam disponibilizadas em uma FAQ (Frequently Asked Questions) com respostas bem objetivas explicando que o NOW é o serviço de vídeo sob demanda que disponibiliza conteúdos gratuítos e para locação.

Em termos de signos metalinguisticos encontrados ao navegar no NET Now, a maioria da informação se concentra na telas de detalhes do filme selecionado. Em geral, as informações são claras e utilizam convenções e padrões utilizados em aplicações desta area. A figura 4 apresenta os signos metalinguisticos da tela de um filme selecionado.

\subsection{Etapa 2 - Inspeção dos signos estáticos}

O mesmo cenário da etapa 1 (a tela inicial do NET Now) foi usado para a inspeção de signos estáticos. Observamos que eles são utilizados para representar as categorias de filmes, bem como, para

\footnotetext{
${ }^{2}$ https://www.nowonline.com.br/
}

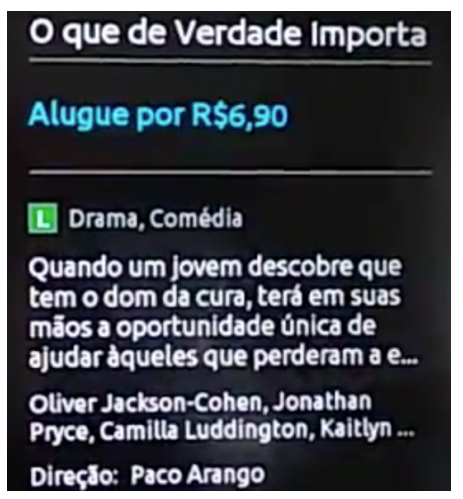

Figura 4: Tela Filme Selecionado

ilustrar cada um dos filmes disponíveis. Além disso, estão disponíveis em diversas partes da aplicação, como menus de ajuda e setas de navegação.

Estes signos estão dispostos em uma área familiar, usando fontes que permitem uma fácil visualização e, em geral, seguem convenções estabelecidas e padrões utilizados em aplicações semelhantes, como o Netflix ${ }^{3}$, HBO GO ${ }^{4}$, YouTube Movies ${ }^{5}$ e entre outros.

\subsection{Etapa 3 - Inspeção dos signos dinâmicos}

Como signos dinâmicos, destacamos os elementos de navegação como breadcrumbs[15] e links de paginação e simbolos de status, como data/hora e transição de telas representado pela mensagem "Carregando". De uma forma geral, todos os signos dinâmicos também seguem convenções estabelecidas e comuns a aplicações web.

A navegação ocorre de diferentes formas na aplicação NET Now, seja através de seleção de categorias de filmes, a utilização de setas para rolagem da lista de filmes e opções disponíveis. Faz uso de signos dinâmicos conhecidos para representar cada opção; eles são interativos, permitindo saber quando estão selecionados, pois sua descrição é destacada e, por fim, suas opções estão em cores que contrastam das cores de fundo da aplicação, permitindo uma melhor visualização.

A tela de busca pode ser acessada pelo menu raiz do sistema conforme a figura 2 (porém essa Busca no menu raiz está localizado no final) e permite ao usuário realizar uma busca textual dos filmes por título, conforme a figura 5, ou por autor/diretor. Nesta tela, é apresentado ao usuário um teclado virtual que, com auxílio do controle remoto, permite a navegação sobre as letras do alfabeto para seleção e o comando de apagar a última letra, para que o usuário possa compor a string de busca.

\subsection{Etapa 4 - Contraste e comparação entre as mensagens identificadas em cada uma das inspeções}

A Tabela 4 apresenta o relatório do MIS, com o contraste e comparação entre as diferentes etapas.

\footnotetext{
${ }^{3}$ https://www.netflix.com/

${ }^{4}$ https://www.hbogo.com.br/

${ }^{5}$ https://www.youtube.com/channel/UClgRkhTL3_hImCAmdLfDE4g
} 


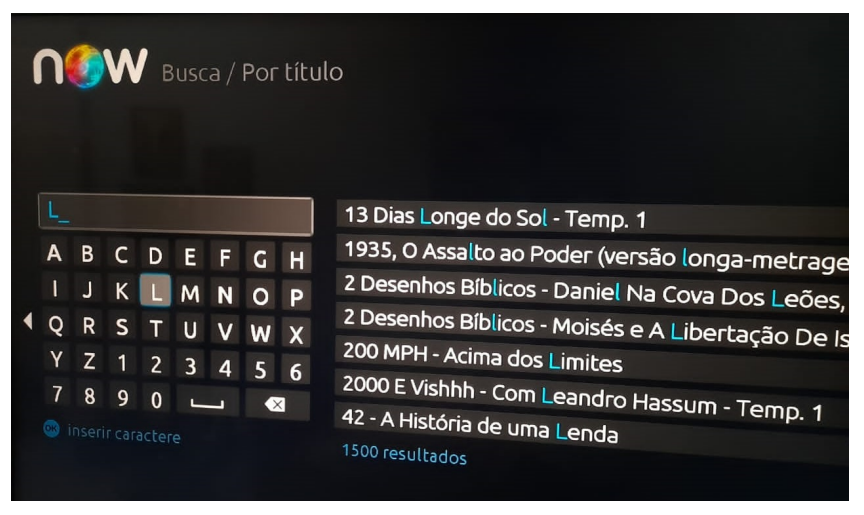

Figura 5: Menu

\subsection{Etapa 5 - Apreciação da qualidade da metacomunicação}

Na última etapa do MIS, isto é, na avaliação final, são propostas adaptações, considerando as limitações do sistema analisado.

Ao observar o menu de navegação isoladamente, como signos (ícones) de setas e árvores de localização, observamos o uso de convenções de maneira apropriada, porém, ao analizarmos os signos em conjunto, com uma perspectiva funcional, podemos notar que os mesmos poderiam gerar dúvidas nos usuários, causando rupturas na comunicabilidade.

O layout do teclado é mostrado na tela e é operado por um controle remoto desenvolvido para esse fim, mostrado figura 1 , que possui, entre outras coisas, 4 teclas para navegação entre os blocos de teclas (para cima, para baixo, esquerda e direita) e 5 teclas para seleção de caracteres (Cima à direita, Baixo à esquerda, Baixo à direita, Cima à esquerda e OK) segue o padrão QWERTY. Por causa da abordagem em 2 etapas da navegação em blocos de teclas usando as teclas de navegação seguida de seleção / digitação usando as teclas de seleção, a abordagem é chamada de navegação e seleção hierárquica[16] .

A funcionalidade de auto-completar, que ocorre a medida que o usuário vai selecionando as letras, funciona exibindo os títulos de filmes ou autores/diretores contendo a string de busca parcialmente formada em seus nomes, listando-os ao lado direito da tela, ilustrado na figura 5. A navegação entre teclado virtual e filmes listados ao lado direito da tela também se mostrou complexa.

A área de tela que comporta a lista de filmes pesquisados, a qual apresenta uma relação de linhas vazias com o texto "Digite um termo para iniciar a busca", parece não seguir padrões e convenções comuns a esse tipo de elemento.

\section{AVALIAÇÃO DE COMUNICABILIDADE}

Considerando o objetivo de analisar os desafios de pessoas idosas na utilização de aplicações desenvolvidas para Smart TV, foram convidados, para participação no MAC, 6 participantes, com idades entre 60 e 80 anos. Um dos participantes, por motivos pessoais, mudou de ideia e preferiu não mais fazer parte do estudo. Portanto a população final do estudo, foi composta de 5 mulheres, conforme Tabela 5. Todos os participantes tinham Smart TV em suas casas
Tabela 4: Relatório MIS

\begin{tabular}{ll}
\hline \hline Questão/ Signos & Avaliação \\
\hline $\begin{array}{l}\text { 1 - Quem é o usuário, o que ele sabe, } \\
\text { em que contexto está? }\end{array}$ & \\
Signos Metalinguísticos & Usuário com habilidade relativa para \\
& navegar com controle remoto da TV. \\
& Conhecimento das teclas e opções \\
desse controle. & Possui experiência com ambientes de \\
& conteúdos e vídeos sob demanda. \\
& Possui uma boa visão \\
& Usuários conhecem muito bem a \\
organização dos pacotes ofertados \\
pela NET.
\end{tabular}

Signos Dinâmicos

Usuários com grande facilidade de navegar entre os menus com capacidade de explorar os menus para descobrir opções muitas vezes "escondidas".
2 - O que este usuário quer fazer,
de que formas preferenciais
e por quê?
Signos Metalinguísticos

Signos Estáticos

Signos Dinâmicos
O Usuário quer encontrar um filme ou documentários ou ouvir músicas.

O usuário gosta de explorar vários filmes e tem tempo para ficar explorando as diversas opções apresentada no Menu de Opções.

\section{O usuário tem tempo para ficar} explorando as diversas opções apresentada no Menu de opções. Não se importa de ficar entrando e saindo nas opções de menu para ter "mais detalhes" sobre o conteúdo. Ex: Ao clicar na opção cinema, a descrição da subcategoria e exibida na tela principal, onde estavam os ícones. 3 - Que sistema o designer
construiu para este usuário? (visão de design)

Como e para quê o usuário deve se comunicar com o sistema? (como funciona)

Signos Metalinguísticos

Signos Estáticos

O serviço é gratuito para os clientes da NET, mas dentro do próprio portal existe a opção para aluguel de filmes e séries, mas usuário descobre se esse é gratuíto ou pago somente quando seleciona o conteúdo .

O Now só disponibiliza para os usuários os conteúdos dos canais que assina no seu pacote de TV. Se o usuário quiser assistir um episódio de determinada série, mas o seu pacote não tem o canal em que é exibida, poderá ver essa série pelo Now

Signos Dinâmicos

NET Now é um serviço de vídeos sob demanda exclusivo para quem é cliente da operadora da NET Virtua.

O usuário tem acesso a filmes e séries. e alguns deles mais de uma opção inteligente na mesma televisão. Mesmo assim, nenhum deles afirmou utilizar os recursos da plataforma avaliada. 


\section{Tabela 5: Perfil Participantes}

\begin{tabular}{llll}
\hline \hline ID & Idade & Sexo & Utiliza Now \\
\hline P1 & 69 & F & Não \\
P2 & 71 & F & Não \\
P3 & 78 & F & Não \\
P4 & 80 & F & Não \\
P5 & 65 & F & Não \\
\hline
\end{tabular}

\subsection{Procedimento de Coleta e Análise dos Dados}

Para a avaliação da Comunicabilidade, vídeos foram gravados para registrar toda a interação do usuário com a aplicação, focando apenas na interface. Após a conclusão de cada interação, os observadores coletaram opiniões, expostas de forma espontânea pelo usuários, sobre os principais desafios encontrado na realização da tarefa solicitada.

De posse dos vídeos, estes foram analisados de acordo com o proposto pelo MAC. Para cada vídeo de cada participante foi criada uma planilha e transcritos todos os passos (ações) executados e, de acordo com esses passos, foram aplicadas as etiquetas de comunicabilidade $^{6}$ já descritas anteriormente na Tabela 1. Na Tabela 6 mostramos um exemplo da transcrição de todos os passos do participante P3, após o processo de etiquetagem.

\section{Tabela 6: Etiquetagem Individual participante P3}

\begin{tabular}{lll}
\hline \hline ID & Ações do usuário e da NET Now & Breakdown \\
\hline 1 & Desceu até o menu "Cinema" & \\
2 & Entrou no menu "Cinema" & Cadê? \\
3 & Explorou o menu "Cinema" & \\
4 & Entrou no menu "Destaques" & Cadê? \\
5 & Explorou todos os filmes disponíveis até o fim da lista & Ué, o que houve? \\
6 & Saiu do NET Now para a NET TV & \\
7 & Voltou ao NET Now sem interromper o estudo & Vai de outro jeito \\
8 & Voltou ao menu anterior "Cinema" & \\
9 & Explorou o menu "Cinema" & \\
10 & Entrou no menu "Especial sucessos do cinema" & Cadê? \\
11 & Explorou todos os filmes disponíveis até o fim da lista & Ué, o que houve? \\
12 & Saiu do NET Now para a NET TV! & \\
13 & Voltou ao NET Now sem interromper o estudo & \\
14 & Entrou no menu "Recomenda" & Cadê? \\
15 & Explorou todos os filmes disponíveis até o fim da lista" & Ué, o que houve? \\
16 & Saiu do NET Now para a NET TV! & \\
17 & Voltou ao NET Now sem interromper o estudo & Vai de outro jeito \\
18 & Voltou ao menu anterior "Cinema" & Cadê? \\
19 & Explorou o menu "Cinema" & \\
20 & Fim do tempo do estudo & \\
\hline
\end{tabular}

\subsection{Resultados}

Ao observarmos as opiniões dos participantes, coletadas após a realização dos testes, já vemos indícios das dificuldades dos participantes em utilizar a plataforma : "É difícil de usar, não tem um lugar dentro de cinema para digitar, para buscar os filmes"(P2); "É dificil de achar as opções, depois que aprende até vai..."(P1); "Parece um labirinto"(P4); "Não tenho paciência"(P3); "O "Buscar"fica escondido"(P1); "Os filmes deveriam ficar somente dentro de "Cinema"'(P2); "Deveria ter um "Buscar"dentro de Cinema"(P2). Dos cinco participantes, somente dois conseguiram atingir o objetivo e encontrar o filme

${ }^{6}$ Todas etiquetagens individuais podem ser acessadas no link https://tinyurl.com/ybg4xd93 solicitado (P1 e P4). Um participante (P2) desistiu logo no início, não querendo continuar e dois (P3 e P5) não conseguiram realizar com êxito a atividade proposta.

Então, com o objetivo de identificar os padrões de ruptura de comunicabilidade, os resultados da etapa de etiquetagem foram consolidados, resultando na Tabela 7 .

Tabela 7: Etiquetagem Total

\begin{tabular}{lll}
\hline \hline ID & Etiquetas/Conversas & Total \\
\hline 1 & Cadê & 11 \\
2 & Vai de outro jeito & 10 \\
3 & O que houve? & 7 \\
4 & Epa & 4 \\
5 & O que é isto? & 3 \\
6 & E agora? & 2 \\
7 & Não, obrigado! & 2 \\
8 & Onde estou? & 1 \\
9 & Por que não funciona? & 1 \\
10 & Pra mim, está bom. & 1 \\
11 & Desisto & 1 \\
12 & Assim não dá & 0 \\
13 & Socorro! & 0 \\
\hline
\end{tabular}

Conforme dados ilustrados na Tabela 7, observamos que das etiquetas de comunicabilidade a que mais se repetiu durante a observação dos vídeos foram a "Cadê? (Where is?)" com 11 repetições, em segundo a que mais se repetiu foi "Vai de outro jeito" com 10, por terceiro "Ué, o que houve? (What happened?)" com 7 repetições e a quarta etiqueta foi "Epa! (Oops!)" com 4. Observamos também que as etiquetas "O que é isto", "E agora" e "Não Obrigado", também ocorreram, mas com uma frequência menor durante os estudos, no máximo de 2 ou 3 repetições.

A etiqueta "Cadê? (Where is?)" é usada quando o usuário espera ver um certo sinal que corresponde a um elemento particular de sua estratégia, mas não consegue encontrá-la entre os sinais expressos pelo designer [11]. Nesse contexto, essa etiqueta pode indicar uma escolha inadequada de organização ou expressão dos signos de interface e um sintoma típico dessa ruptura de comunicação ocorre quando o usuário navega por vários elementos de interface [17].

Observamos que durante a interação dos usuários com menu da tela inicial da NET Now (figura 2), esses buscaram encontrar o filme solicitado, conforme um dos exemplos de etiquetagem da Tabela 6 . O participante P3 entra na opção do menu "Cinema" e explora todos os filmes dessa categoria, mas não encontra (passos 1, 2 e 3). Depois retorna ao menu e seleciona a opção "Destaques" e explora (passos 4 e 5). Ainda tenta outra opção do menu, a "Recomenda" e explora todos os filmes desta categoria (pasos 14 e 15). Todos esses passos descritos demontram que o participante procura pelo filme, em diversas opções do menu, mas não encontra. Somente os participantes P1 e P5 conseguiram navegar pelas opções do menu e econtrar a opção "Busca" e assim realizar a busca textual do filmes, por título, conforme a figura 5.

A "Vai de outro jeito" foi a segunda etiqueta de comunicabilidade que mais se repetiu durante os testes. Essa é utilizada quando o usuário não reconhece o caminho de interação preferido pelo designer (geralmente mais curto e simples) ou não consegue percorrê-lo, e então é obrigado a seguir por um outro caminho de interação [17]. Geralmente, pode indicar uma falta de correspondência entre 
a visão do designer e a expectativa do usuário sobre como um objetivo do usuário pode ser alcançado. Observamos que por diversas vezes e com quase todos os participantes aconteceu de eles não reconheceram o caminho mais "curto" para encontrar o filme, e tentaram "de outro jeito" voltando a opção do menu "cinema" diversas vezes e explorando os filmes dessa categoria, conforme exemplo da etiquetagem do participante P3 na Tabela 6, no passo 18.

A etiqueta "Ué, o que houve? (What happened?)", que ficou em terceiro lugar, entre as que mais repetiram, é usada quando o usuário não percebe ou não compreende as respostas do sistema decorrentes de uma ação ou evento anterior. Pode indicar uma ambiguidade na expressão do signo que o designer utilizou para comunicar a resposta do sistema ou falta de familiaridade do usuário com essa expressão. Nesse caso, é comum o usuário repetir a operação realizada [17]. Observamos que essa etiqueta ocorreu várias vezes na mesma situação, quando o usuário tenta voltar ao menu principal, sair de dentro da opção do menu anteriormente selecionada, mas acaba selecionando a opção do controle remoto em que sai do NET Now, assim fica tentando entender "o que houve ?". Outra situação foi quando o usuário P1 digitou na opção de busca "LALALAND" - todos os caracteres juntos, sem espaço - e, como não retornou o esperado, ficou tentando entender "o que houve ?".

Mais uma etiqueta que apresentou uma quantidade significativa de repetições foi "Epa! (Oops!)". Ela é usada quando o usuário comete um erro momentâneo e o corrige imediatamente. Percebe que deu um passo errado e geralmente ativa a função "desfazer" imediatamente. No entanto, se a tentativa de corrigir seu erro se transformar em uma longa busca por uma maneira de cancelar os efeitos de um deslize, então indica um problema de comunicação muito sério [11]. Quanto maior o esforço e tempo necessários para desfazer o engano cometido, maior será a gravidade dessa ruptura de comunicação [17]. Observamos essa etiqueta geralmente quando o usuário conseguiu entrar na opção do menu "Busca" mas não conseguiu digitar as letras corretamente, precisando voltar para corrigir ou para inserir espaços entre as palavras, no caso necessários entre "La La Land".

Conforme dados ilustrados na Tabela 7, observa-se uma concentração de rupturas sobre as etiquetas "Cadê", "Vai de outro jeito", "O que houve" e "Epa". Porém as etiquetas "O que é isto", "E agora" e "Não Obrigado", também ocorreram com menor frequência durante os estudos.

A etiqueta “O que é isto?” pode indicar o uso de um código expressivo inadequado, não familiar ao usuário. O sintoma típico é o usuário navegar pela interface procurando por alguma dica, que explique o significado codificado dos signos não compreendidos. Observamos que essa etiqueta ficou visível no momento em que os usuários conseguiram entrar na opção de menu "Busca" mas não entenderam os signos apresentados para buscar o filme desejado.

A “E agora?” é quando o usuário não sabe o que fazer em determinado momento para concluir a tarefa e procura descobrir qual deve ser o seu próximo passo, o sintoma típico é também ficar navegando pelos elementos da interface. Essa etiqueta ficou evidente quando o usuário conseguiu digitar corretamente o nome do filme na opção do menu de "Busca", mas não consegue entender como fazer para passar para a parte da direita da tela, conforme ilustrado na figura 5 e então selecionar o filme. Ou outra situação é quando o usuário selecionou a opção do menu "Recomenda", voltou ao menu principal e ficou sem saber para onde seguir.

Já com a etiqueta “Não, obrigado!” o usuário decide seguir por um caminho não preferido pelo designer, mesmo conhecendo e sabendo percorrê-lo. A diferença entre as etiquetas “Não, obrigado!” e "Vai de outro jeito" depende de o usuário estar ou não ciente dos caminhos de interação oferecidos e preferenciais. No primeiro caso, o usuário conhece o caminho, mas decide seguir por outro, porém no segundo o usuário não conhece e por isso tem de percorrer um outro [17]. Observamos que quando o usuário, ao entrar na opção do menu "Busca" e começa a digitar o nome do filme "La La", já aparece na parte direita da tela o nome para que ele possa selecioná-lo, porém os usuários (P1 e P5) preferiram continuar e digitar o nome completo do filme.

\section{DISCUSSÃO}

Analisando-se conjuntamente os resultados obtidos, percebemos que, na etapa 4 do MIS, principalmente na análise de signos dinâmicos, o designer espera usuários com grande facilidade de navegar entre os menus, com capacidade de explorar e de descobrir opções muitas vezes "escondidas"; porém, o público observado apresenta grandes dificuldades nesta exploração, conforme visto na etapa de etiquetagem do MAC, com a concentração de rupturas sobre as etiquetas "Cadê". Ou seja, este público não encontra a facilidade esperada.

Também, ao observarmos as análises dos signos metalinguísticos, estáticos e dinâmicos propostas pelo MIS, percebemos que, de uma forma geral, são seguidas as convenções estabelecidas e comuns a aplicações web. Destaca-se, porém, que em estudos como o apresentado por Sales [18], o acesso a web, por usuários idosos, pode ser dificultado devido à forma como as páginas são estruturadas ou por falta de navegadores apropriados. Segundo os autores, a bibliografia sobre recomendações de acessibilidade na web para pessoas idosas é reduzida e faltam iniciativas que tratem desta perspectiva.

Para Czaja e Lee [19], não ter acesso ou não ser capaz de usar a tecnologia colocará os idosos em desvantagem em termos de sua capacidade de viver independentemente. Os autores afirmam ainda que muitas vezes, os designers não consideram os idosos como usuários ativos de tecnologia e as interfaces são projetadas sem levar em consideração as mudanças nas habilidades relacionadas à idade. Assim como, muitos designers têm compreensão limitada do processo de envelhecimento ou de como projetar sistemas para acomodar esse grupo de usuários [19].

Os resultados consolidados da etapa de etiquetagem do MAC, apresentados na Tabela 7, demostram uma concentração de rupturas sobre as etiquetas "Cadê", "Vai de outro jeito", "O que houve" e "Epa". A ruptura identificada pela expressão "Cadê" ocorreu na maioria das situações, com onze sinalizações ao longo dos estudos, indicando uma dificuldade geral de todos os usuários em encontrar alguma opção nos menus que auxiliassem na seleção do filme desejado. Já a ruptura identificada pela etiqueta "Vai de outro jeito", demonstra a desistência do usuário e busca por alternativas para atingir o objetivo. Por fim, a ruptura sinalizada pela etiqueta "O que houve?", indica uma possível dificuldade de vincular uma ação realizada com uma reação da aplicação. 
De uma forma geral, a análise das quatro principais etiquetas de comunicabilidade que mais se repetiram nos testes revelou um usuário um tanto "confuso" no ambiente da plataforma digital NET Now. As etiquetas refletiram que o usuário esperava localizar o filme e não conseguiu encontrá-lo, buscou em caminhos diferentes, não reconheceu o caminho de interação preferido pelo designer (mais curto e simples), e, então, sentiu-se obrigado a seguir por um outro caminho de interação.

Observamos consonâncias ao relacionarmos as etiquetas de comunicabilidade propostas pela engenharia semiótica, com as opiniões dos usuários coletadas após realizações dos testes: "É difícil de usar, não tem um lugar dentro de cinema para digitar, para buscar os filmes"(P2); "É difícil de achar as opções, depois que aprende até vai..."(P1); "Parece um labirinto"(P4); "Não tenho paciência"(P3); "O "Buscar"fica escondido"(P1); "Os filmes deveriam ficar somente dentro de "Cinema"'(P2); "Deveria ter um "Buscar"dentro de Cinema"(P2).

Estas opiniões, expressas pelos participantes do MAC, foram importantes para que fosse possível comparar com os padrões de ruptura de comunicabilidade obtidos na etapa de etiquetagem.

\section{LIMITAÇÕES DO ESTUDO}

Uma das limitações desse estudo se refere ao número pequeno de participantes e de ser uma amostra por conveniência. Apesar de este número estar adequado às recomendações do método em questão (MAC), outros perfis poderiam ter agregado novas contribuições à análise. Destaca-se que, mesmo sendo uma amostra por conveniência, as questões éticas relacionadas a um estudo deste tipo foram consideradas, como a apresentação e assinatura de um Termo de Consentimento Livre e Esclarecido antes do início de cada teste.

Um fator que não entrou no escopo do trabalho é a avaliação do uso de Controles Remotos de Televisores. Um dos participantes do estudo comentou que se fosse uma interface de toque semelhante ao smartphone, seria muito mais fácil. Gritton [20] levanta essa questão e responde como poderíamos tocar na televisão quando estamos sentados e distantes da sua tela.

Outra questão que também não fez parte do escopo desse trabalho é a análise comportamental dos participantes. Devido a distância da tela e da necessidade de um controle, o participante tem muito mais distrações. Percebemos que algumas interações dos participantes com o sistema foram prejudicadas por distrações, pois os participantes estavam lendo as legendas do controle ao clicar um botão e perdiam o feedback de ação/transição da interface. Este é um tópico que também necessita maiores investigações.

\section{CONSIDERAÇÕES FINAIS}

Aplicar ambos os métodos de avaliação foi positivo. Apesar do MIS nos mostrar possíveis problemas de comunicação, identificamos poucos capazes de comprometer a experiência do usuário. Já o MAC evidenciou que usuários idosos têm muitas dificuldades com o sistema. O uso conjunto dos dois métodos foi complementar, levando a um maior entendimento do cenário em questão.

Assim como Tavares e Souza [21], acreditamos que o Estado deve oferecer recursos para o ensino das novas tecnologias (inclusão digital), para que os idosos consigam exercer a sua cidadania, sem o sentimento de exclusão da sociedade por não acompanharem os avanços tecnológicos. Os autores salientam a importância de promover ações e políticas de inclusão digital como uma forma de oportunizar ao idoso a possibilidade de usufruir da gama de conhecimento que na atualidade estão disponíveis nos ambiente web (revistas, jornais, portais acadêmicos, blogs).

Por fim, considerando a expectativa de longevidade da população, como destacado no início deste trabalho, pesquisas com foco neste público alvo são, cada vez mais, necessárias para que eles possam ter, garantido, o acesso a todos os sistemas/recursos que desejarem, sem necessitarem auxílio externo para esta interação.

\section{REFERÊNCIAS}

[1] Rodrigo Paradella. Smart tvs crescem, mas 11,9 milhões de brasileiros ainda dependem de sinal analógico. ibge - agência de notícias. 2019. URL https: //tinyurl.com/yxn95ex5.

[2] IBGE. Pnad contínua tic 2018: Internet chega a 79,1\% dos domicílios do país. ibge - agência de notícias., 2020. URL https://tinyurl.com/yxqdm5j3.

[3] Lucas Freitas and Sandra Lima. Da tv para a netflix : a mudança de estratégia das marca. In Intercom - Sociedade Brasileira de Estudos Interdisciplinares da Comunicação(XVIII Congresso de Ciências da Comunicação na Região Nordeste), number 1, page 16, 2016.

[4] Jornal da USP. Em 2030, brasil terá a quinta população mais idosa do mundo, 2018. URL https://jornal.usp.br/atualidades/em-2030-brasil-tera-a-quinta-populacaomais-idosa-do-mundo/.

[5] Tiago Manuel Marques da Silva Moreira. NONIUS. TV na SMART TV LG PRO: Centric. PhD thesis, 2012.

[6] Suelen Backes. Produção e consumo de vídeos on-line: análise de práticas e técnicas para o desenvolvimento de influenciadores digitais profissionais a partir do youtube. Master's thesis, Pontifícia Universidade Católica do Rio Grande do Sul, 2019.

[7] Iftikhar Alam, Shah Khusro, and Muhammad Naeem. A review of smart tv: Past, present, and future. In 2017 International Conference on Open Source Systems \& Technologies (ICOSST), pages 35-41. IEEE, 2017.

[8] Clarisse Sieckenius de Souza. The semiotic engineering of user interface languages. International journal of man-Machine Studies, 39(5):753-773, 1993.

[9] Clarisse Sieckenius De Souza, Carla Faria Leitão, Raquel Oliveira Prates, and Elton José da Silva. The semiotic inspection method. In Proceedings of VII Brazilian symposium on Human factors in computing systems, pages 148-157, 2006.

[10] Natália S. et al. Uma análise comparativa dos métodos de avaliação de sistemas colaborativos fundamentados na engenharia semiótica. In Proceeding IHC '13 Proceedings of the 12th Brazilian Symposium on Human Factors in Computing Systems, pages 218-227, Porto Alegre, BR, 2013. Brazilian Computer Society.

[11] Clarisse S. de Souza and Carla F. Leitão. Semiotic Engineering Methods for Scientific Research in HCI. Morgan Claypool Publishers, 2009. ISBN 9781598299458.

[12] Clarisse S De Souza, Raquel O Prates, and Simone DJ Barbosa. A method for evaluating software communicability. Monografias em Ciência da Computação. Departamento de Informática. PUC-RioInf, 1200(1):11-99, 1999.

[13] Claro NET Now. O que é o net now?, 2020. URL https://www.minhaconexao. com.br/blog/net-now/.

[14] NET. Conheça as funções do controle remoto net, 2020. URL https://www.net. com.br/tv-por-assinatura/recursos/controle-remoto.

[15] Global AD. O que são breadcrumbs?, 2020. URL http://globalad.com.br/blog/oque-sao-breadcrumbs/.

[16] Arpan Pal, Debatri Chatterjee, and Debnarayan Kar. Evaluation and improvements of on-screen keyboard for television and set top box. In 2011 IEEE 15th International Symposium on Consumer Electronics (ISCE), pages 625-630. IEEE, 2011.

[17] Simone D. J Barbosa and Bruno S. da Silva. Interação humano-computador. SBC, Sociedade Brasileira de Computação. Elsevier Editora Ltda, 2010. ISBN 978-85352-3418-3.

[18] Márcia Barros Sales. Desenvolvimento de um checklist para a avaliação de acessibilidade da web para usuários idosos dissertação de mestrado submetida ao programa pós-graduação em engenharia de produção. 2002.

[19] Sara J Czaja and Chin Chin Lee. The impact of aging on access to technology. Universal access in the information society, 5(4):341-349, 2007.

[20] Charles WK Gritton. What? s wrong with smart tv?: How to improve user experience. IEEE Consumer Electronics Magazine, 2(4):40-43, 2013.

[21] Marília Matias Kestering Tavares and Samara Tomé Correa de Souza. Os idosos e as barreiras de acesso às novas tecnologias da informação e comunicação. RENOTE-Revista Novas Tecnologias na Educação, 10(1), 2012. 